\section{Reflections on undergraduate teaching} To the Editor: After 18 years of largely being out of undergraduate teaching of medical students, I am once again immersed. It is the same as it was, but it is also very different. In trying to make sense of this difference, I reflect on what I have experienced since returning to the clinical learning environment.

I trained in a large impersonal teaching hospital in London in the 1980s. All consultants were treated like gods. Professors were above them. Matrons were just below them and, working down the chain, medical students were to be seen but rarely heard, spoke only when spoken to, and were used for tasks on the wards that the student nurses felt were beneath them. The ward rounds were staged, dramatic and to be feared. As students, we were expected to be smart and presentable - I was chastised for wearing trousers.

I arrived in South Africa (SA) in 1994 and joined Stellenbosch University (SU)'s surgical department as a registrar. I found the medical students to be polite and slightly old fashioned compared with their European counterparts. Then I moved to private practice and for the last 18 years have had minimal involvement with undergraduates. Now I am fortunate enough to have been given the opportunity to return to a teaching position and find myself once again engaging with medical students in the wards. So, what has changed?

I am not the main source of information. Their phones are. Google knows far more than I do. However, what Google does not teach them is how to talk to and examine a patient. Many are more comfortable reading notes from a screen, rather than communicating with patients. The internet, while being a resource of knowledge, is not a source of understanding. Having immediate access to small amounts of information (and misinformation) results in the students not having to interpret, comprehend or retain information.

Another striking change relates to dress code. While my opinion regarding students turning up inappropriately clothed is possibly not an issue, what the patients think of the student doctors' appearance is important, and often their concept of how a health professional should look is more conservative than mine. This discussion has received much attention internationally, with no obvious solution. ${ }^{[1]}$

The most concerning change, however, is absenteeism. I have not yet had a group of students who have all attended for the full period of their allocated rotation. This is not unique to our firm. Many of my colleagues (both here and abroad) have made the same observation. I have had many discussions with colleagues and students to try to understand what has altered, and have come to the conclusion that there are real and challenging differences.

I don't believe the students work harder than we did, that they are 'abused' more, and expected to know more, and I don't think they are less strong. The causes are more complex.

Millennials have been raised in an individualised world. Family life revolves around the younger generation and, in turn, their lives revolve around social media. This generation has been bought up with instant communication and response. They have been raised in a world where their peers seem to have ideal lives. That perfect world is in stark contrast to the realisation that being a doctor is not at all glamorous.

The need for psychological help is more accepted among students and is more accessible. This results in absenteeism. In 2017, a study assessing medical students from the University of the Free State, Bloemfontein, SA, showed a prevalence of $25-30 \%$ when measuring depression, anxiety and stress. ${ }^{[2]}$ In the UK, a $B M J$ survey showed that $30 \%$ of medical students have received help for a mental medical

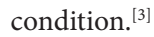

How can we give our students the support they need to succeed in obtaining their degree and yet prepare them for a clinical career that is filled with rewards but interspersed with times of loneliness and feelings of isolation? Medical education has traditionally been about problem-solving, aimed at producing clinicians, and a set syllabus. However, not all students who choose medicine are suited to a clinical career. Dr Maria Phalime, in her book, Postmortem, ${ }^{[4]}$ wrote about her decision to leave her job, and highlighted the problem of burnout among doctors. Clinical medicine is facing increasing financial pressure as the population ages and has to consider alternative ways of providing healthcare. Out of necessity, this will include development of alternative health systems and the increasing use of technology.

Perhaps it is time that medical education became more diverse, offered non-compulsory options during the degree and provided training for both clinical and non-clinical careers. This may take pressure off medical students who feel daunted by their choice of a clinical career, and encourage graduates to become solution seekers rather than problem solvers.

Acknowledgement. The author wishes to thank Prof. S van Schalkwyk for her contribution.

\section{Jenny Edge}

Division General Surgery, Department of Surgery, Faculty of Medicine and Health Sciences, Stellenbosch University, Cape Town, South Africa

dr@jennyedge.co.za

1. Oxtoby K. What should medical students wear? Student BMJ September 2017. http://student.bmi.com/ student/view-article.html?id=sbmi.j3207 (accessed 29 January 2019).

2. Van Zyl PM, Joubert G, Bowen E, et al. Depression, anxiety, stress and substance use in medical students in a 5-year curriculum. Afr J Health Professions Educ 2017;9(2):67-72. https://doi. org/10.7196/AJHPE.2017.v9i2.705

3. Medical students with mental health problems do not feel adequately supported. Student BM] September 2015. www.bmj.com/company/wp-content/uploads/2014/07/student-bmj-survey.pdf
S September 2015. Www.

4. Phalime M. Postmortem: The Doctor Who Walked Away. Cape Town: Tafelberg, 2014

S Afr Med J 2019;109(3):136. DOI:10.7196/SAMJ.2019.v109i3.13865 